\title{
Our experience with surgical treatment of lesions of nervus facialis
}

\author{
V. Matejčík and G. Pénzesová
}

Department of Neurosurgical Clinic of the Medical Faculty of Comenius University Academician L. Dérer Faculty Hospital. Bratislava. Slovak Republic

Summary

Objective. The study presents the results of reconstruction surgery of lesions on $\mathbf{n}$. facialis with $\mathbf{n}$. hypoglossus and $n$. accessorius performed in our clinic.

Patient group and methods. 10 patients were treated by anastomosis of $n$. facialis with $n$. hypoglossus (HFA), 1 patient by anastomosis of $n$. facialis with $n$. accessorius (AFA). All operations were performed under the microscope; HFA and AFA anastomoses were sewed without tension at perineurium. The techique of suturation of facial nerves did not differ from the suturation of peripheral nerves in extremities. For the connection of n. VII-XII was not used plasma pasting. We did not use end to side anastomosis or reconstruction of n. VIIVII in pontocerebellar angle, in pyramid, or symetrical anastomoses of $\mathbf{n}$. VII-VII, in any case. The results were objectivized by a VI grade Brudny's modification of House-Brackman classification introduced originally for scaling of the outcome of HFA anastomosis. In this study, this classification has been used for the objectivization of AFA anastomosis results.

Results. Reconstruction surgery by HFA and AFA resulted in all cases in grade III of the scale. Glossal hemiatrophy or atrophy of $\mathbf{m}$. sternocleidomastoideus and $\mathbf{m}$. trapesius were observed in patients treated by cross anastomosis with $\mathbf{n}$. hypoglossus or $\mathbf{n}$. accessorius. In patients treated by HFA and even more pronounced in patient with AFA anastomosis, minute synkineses in the region of labial angle, chin, also in the region of lower eyelid, occurred in the excited emotional state or during a long-lasting speech.

Major diskincses were not observed in any of reported treatments. Recovery in older patients up to 60 years was coming more slowly, in one case after 6 months.

Conclusion. Compared to AFA anastomosis, HFA anastomoses resulted in improved mimics and synkineses present here were finer. We prefer HFA anastomosis also because the discomfort caused by atrophy of ni.

Recibido: 11-04-07. Aceptado: 6-06-.07 trapesius and ni. sternocleidomastoideus was apparently more perceived by patient treated by AFA than the negative effects of hemiatrophy reported by patients treated by FIFA.

KEY WORDS: Facial nerve. Reconstruction surgery. Hypoglossus nerve. Accessories nerve.

Nuestra experiencia en el tratamiento de lesiones del nervio facial

\section{Resumen}

Objetivo. Este trabajo presenta los resultados de cirugía reparativa de lesiones del nervio facial con anastomosis con el nervio hipogloso y con el accesorio en nuestra clínica.

Grupo de pacientes y métodos. Se trataron 10 pacientes con anastomosis del nervio facial con hipogloso (AFH) y un paciente con anastomosis con el nervio accesorio, (AFA). Todas las operaciones se realizaron con microscopio. Todas las anastomosis se hicieron sin tensión en el perineuro. La técnica de sutura no difería de la habitual en otros nervios periféricos. Para la unión del VII-XII no se utilizó pegamento de plasma. No utilizamos anastomosis latero-terminal ni anastomosis de los extremos del VII lesionado en el ángulo pontocerebeloso, en la pirámide ni tampoco del VII-VII simétricos. Los resultados se objetivaron con el grado VI de Brudny, modificación de la escala de House-Brackman, clasificación propuesta para medir el pronóstico de las lesiones del facial. En este estudio se ha utilizado para objetivar el resultado de la anastomosis.

Resultados. La reconstrucción quirúrgica por anastomosis dio como resultado un grado III de la escala. Se observó hemiatrofia de la lengua y del trapecio esternocleidomastoideo. Se apreciaron mínimas discinesias en la comisura labial, mejilla y párpado inferior

Abreviations. AFA: accessorius facialis anastomosis. HFA: hypoglossus facialis anastomosis. 
en situaciones de alteración emocional o después de hablar largamente. No hubo discinesias importantes en ningún caso. La recuperación fue lenta en pacientes de más de 60 años; en un caso después de seis meses.

Conclusión. Si se compara la AFH con la AFA el mejor resultado se obtuvo con la anastomosis del hipogloso, tanto en la mímica como en las sincinesias. Preferimos la AFH porque la atrofia del esternocleidomastoideo y trapecio eran más molestas para el paciente que las producidas por la hemiatrofia lingual.

PALABRAS CLAVE: Nervio facial. Cirugía reconstructiva. Nervio hipogloso. Nervio accesorio.

\section{Introduction}

Nervus facialis conducts not only motor fibres to mimic muscles but also parasympatic efferent fibres and tastesensing afferent fibres, as well as motor fibres to the ear muscles and masticatory muscles ${ }^{8}$.

The nerve is composed of three segments:

1. Intracranial

2. Pyramidal (canalis facialis)

3. Peripheral

Injury in the first two segments causes the paralysis of one half of the face, defects in ear-drum lünction, in taste perception and in secretion. Injuries in the pyramidal output and foramen stylomastoideum result only in motor defects.

Lesion of facial nerve may be caused by injury. If the nerve is damaged by a sharp object (e.g. glass), it should be treated immediately. In the cases where direct re-connection is impossible, reconstruction surgery is performed by means of neural graft, or by a reconstruction heterotopic cross-innervation which includes another nerve that is completely or partially sacrificed. In the latter case, the function of one nerve is sacrificed for a gravely imperfect function of another nerve. The complete cross anastomosis includes connection of the whole nerve while only a portion of the nerve is used for the partial anastomosis. A lesion of facial nerve is the only indication of cross-reinervation that has been clinically justified. The pre-conditions for the successful cross-reinervation are much more complex than the pre-conditions for a direct re-joining of the nerve.

The paresis of damaged and inaccessible proximal end of nervus facialis has been resolved by anastomosis using nervus hypoglossus, nervus accessorius and the distal part of nervus facialis for more than 100 years. The first known successful reconstruction surgery of $\mathrm{n}$. facialis by the use of n. hypoglossus was reported in $1900^{10}$.

The reliability of this first surgical procedure is unequivocal. Problems that may be present here are linked to tongue hemiatrophy (speech, swallowing) or sometimes to hypertonia, synkinesis and mimic defict. Anastomosis with $\mathrm{n}$. accessorius is acompanied by atrophy of $\mathrm{n}$. sternocleidomastoideus and $\mathrm{n}$. trapesius.

Facial expressions represent a significant form on unconscious communication. Its absence intensifies the feeling of isolation. In addition to cosmetic defects, lagofthalmus is the major reason to the indication for facial reinervation. The capability of reinervation of facial muscles is preserved for a significantly longer time periods than it is in the case of skeletal muscles.

Irreversible fibrotic changes may occur in 3 years after the denervation, but the time period up to 20 years has been also observed ${ }^{13}$. Successful treatment after 5-21 years have been reported in the literature ${ }^{5}$. A complete recovery of the functions of mimic muscles after the injury of nervus facialis is the ideal condition. The attempts to reach this aim last for more than one and half century without full success. Ideal results of facial functional rehabilitation should include:

1. Symmetry in the quiescent state

2. Symmetry of the conscious movements

3. Improvement of the activity of oral, nasal and ocular muscles.

Although surgical reconstruction of the paresis of $n$. facialis has a major psychological and emotional impact on the patient, it is necessary to let them know that the success rate of the treatment is about $90 \%$ and the line mimics will not be reconstituted. Even the optimal performance of the surgery that will restore the gross facial movements will not reconstitute the fine emotional facial movements since the differentiated activity between individual rani is impossible due to aberrant regeneration. Involuntary emotional mimics will be never recovered. The aim of the presented report is to compare the effectiveness of HFA and AFA anastomoses.

\section{Patients and methods}

11 patients were treated by microsurgery on the Neurosurgical clinic in Bratislava in the time period of six years. All patients showed a complete lesion of $\mathrm{n}$. facialis. The reasons of the paralysis of $\mathrm{n}$. facialis included:

- a tumor of pontocerebral angle (neumoma acustici) in 10 patients

- damage after Jannett surgery indicated by pain in 1 patient.

The group of 11 treated patients consisted 3 females. Patient age ranked from 25 to 77 years with the average age of 46 years. The average interval from the diagnosis of the damage to the surgery was 7 months. We preferred cross anastomosis with $\mathrm{n}$. hypoglossus -10 and with $\mathrm{n}$. accessorius-- 1 , for the treatment of the paresis of nervus facialis. These methods were considered in cases of the absence 


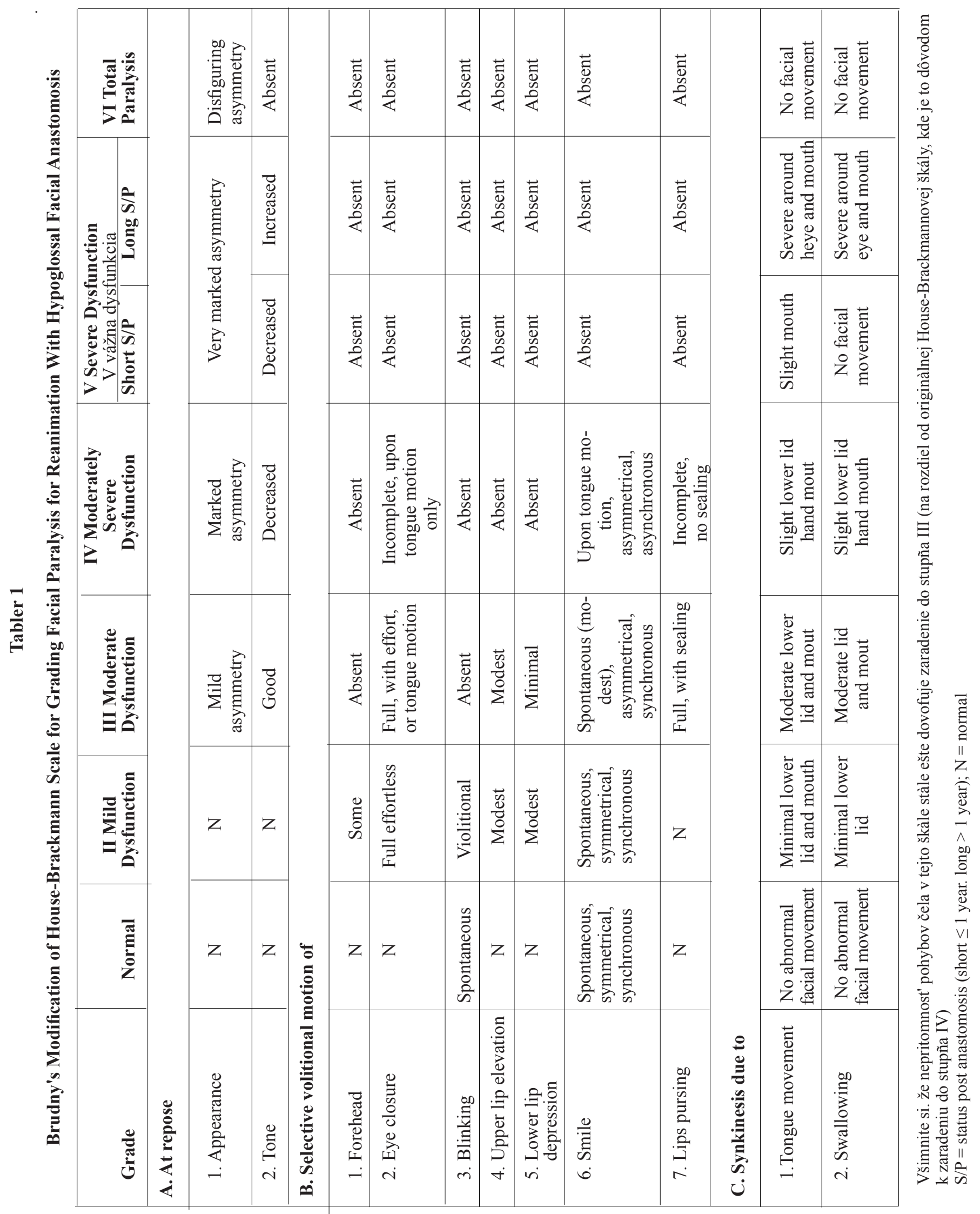


Table 2.

Classification of patients according to the type of reconstruction surgical treatment of $n$. facialis

\begin{tabular}{|l|c|c|c|c|c|}
\hline \multirow{2}{*}{$\begin{array}{l}\text { Character of } \\
\text { reconstruction } \\
\text { surgery }\end{array}$} & \multirow{2}{*}{$\begin{array}{c}\text { Number of } \\
\text { patients }\end{array}$} & \multicolumn{4}{|c|}{$\begin{array}{c}\text { Results according to Brody modification } \\
\text { of the House-Brackmann scale }\end{array}$} \\
\cline { 2 - 6 } & & I & II & III & IV \\
\hline HFA & 7 & - & - & 7 & - \\
\hline AFA & 1 & - & - & 8 & - \\
\hline Total & 8 & - & - & 8 & - \\
\hline
\end{tabular}

of the innervation of facial muscles by the proximal part of n. facialis.

In come cases -2 it is possible to join the descendent ramus of $\mathrm{n}$. hypoglossus with the distal part of $\mathrm{n}$. hypoglossus with presumed prevention of the glossal hemiatrophy.

Patients were monitored at least for 12 months after the surgery. Brudny modification of the House-Brackmann scale $^{9}$ was used for the evaluation of all surgical interventions (Table I ).

The results of EMG examinations revealed denervation in all patients. Post-treatment EMG examinations were performed repeatedly in all patients. The analysis of the results of post-treatment examinations was performed with respect to the character of the treatment.

\section{Results}

The final cosmetic effect did not include a full functional recovery in any case. Grade III of Brudny classification was obtained for all cases of HFA and AFA (Table 2).

The most frequently performed anastomosis was HFA - 10 accompanied by AFA - 1. The first mentioned (HFA) yielded better results.

Facial symmetry was achieved in all patients, defects in swallowing or dysartria were not observed in any of treated patients. All patients showed tarsorrhaphy in the initial phase of the paralysis of $n$. facialis. All patients were able to close eyelid completely (with an effort in the case of AFA anastomosis). Keratitis was not found in any of the cases. All cases showed good results with respect to the recovery of muscle tonus ant trphic state. The fine motoric activity was absent, however, patients could lose the eyelid well. Our observations indicate that HFA anastomosis results in a good peripheral innervation, recovery of facial tonus and facial movements. Two attempts to prevent the hemiautrophy attic tongue by a connection of descendent rams of $n$. hypoglossus with the distal part of $n$. hypoglos- sus can be evaluated as unsuccessful in this respect because glossal hemiautrophy could not be prevented here. In the case of HFA and AFA anastomoses were observed minute synkineses in the region of labial angle, chin and lower eye lid. More severe synkineses were observed after the AFA anastomosis, especially in the excited state or after longer speech.

Re-innervation appeared up to 2 - 4 months past the reconstruction surgery in all patients, also up to 7 months in oldier patients.

Post-treatment EMG was significantly restored except of the superior rams leading to $\mathrm{m}$. frontalis, however, the functional results were unsatisfactory.

\section{Discussion}

Reinervation of facial muscles after $n$. VII damage is important for patient from functional and social reasons. The results of facial muscles reinervation were unsatisfactory, thereby is still important dealing with this problem.

Although our study is only thin survey of the proper operations and results, n. VII is not the only nerve where is the cross anastomoses usage. We did not mentioned in our work about cross anostomoses in the treatment of brachial plexus injuries, and reconstructions of $\mathrm{n}$. VII-VII in pontocerebellar angle in pyramid observed in work $\mathrm{M}$. Samii (1974), by extrapyramidal pathway (N. Dott, 1958), or symetrical anastomoses of n. VII-VII (Smith, Scara Mella,Anderla 1971), etc.

Restoration of muscle activity in HFA and AFA anastomoses requires not just a perfect peripheral re-innervation but also a complete rebuilding of the central mechanisms of motility analyser based on a complete functional connection of $n$. hypoglossus or $n$. accessorius with the motile region of $n$. facialis. The degree of the recovery of voluntary movements after reconstruction surgery of $\mathrm{n}$. facialis depends not only from the age but also on patient's moti- 
vation. The information about the success of suturation and about the re-innervation of mimic muscles can be obtained from the general EMG. The worst results are usually observed for $\mathrm{n}$. frontalis ${ }^{11}$. In spite of a weak and incomplete re-innervation of $\mathrm{m}$. frontalis, the innervation of $\mathrm{m}$. zygomaticus was very efficient. The ultimate cosmetic effect -a normal functional recovery- has not been obtained in any of reported cases ${ }^{6}$.

In more than the last four decades, several authors appraised hypoglosso-facial anastomoses as a reliable method for the re-innervation of facial muscles ${ }^{14}$. We observed insufficiency in fine regional movements independently on other face regions as well as the absence of emotional movements on the paralyzed side. Current priority in constitution of anastomoses between $\mathrm{n}$. VII and $\mathrm{n}$. XII is end to side technique, $n$. XII left partially preserved to prevent glossal atrophy. In our two cases of hypoglossofacial anastomosis, hemiatrophy of the tongue could not be prevented even by distal re-innervation from $\mathrm{n}$. hypoglossus rami. Hypoglossofacial anastomosis ensures face symmetry and prevents the atrophy of facial musculature. The group of patient that showed facial symmetry in relaxed state as well as voluntary closing the eyelid did not achieve facial symmetry during the speech.

Comparably to Balance ${ }^{3}$ we registered an inferior result for AFA anastomoses. A slight assymetry of the quiesecent face and difficult eye closing represent an unfavourable result observed for the $\mathrm{n}$. facial is $-\mathrm{n}$. accessories anastomosis, however, the joint movements of shoulder and face were not registered. Hypotrophy of $\mathrm{m}$. sternocleidomastoideus and $\mathrm{m}$. trapesius were observed in this case.

Coonley $^{2}$ reported good muscular tonus in $95 \%$ of all patients. When the hypoglossofacial anastomosis could be performed during first two years after the injury, reliable muscular tonus was present in $98 \%$ of patients. We achieved a very good or good result (Grade III of the scale) in all cases of reconstruction surgery. Fine synkineses in an excited emotional state or after a long speech were observed for all reconstruction surgical treatments. These synkineses were most pronounced for AFA anastomosis. Similar result was reported also by authors of other clinical studies ${ }^{6,12,14}$. The incidence of synkineses is inversely proportional to the quality of re-innervation: the better the re-innervation, the less frequent are the synkineses. No case of spontaneous or severe synkinesis has been observed in our patients in this study.

Inferior results in cross anastomosis may be caused by two unfavourable factors:

- incomplete peripheral regeneration

- low probability for a central re-building to a new function.

The result of this treatment will thus be always worse than a direct connection or connection via the neural graft originating from the original nerve.

In spite of all facts mentioned above, we do not regard our results as definitively positive ones. Intentional and unintentional facial movements utilize different pathways, although most often mediated by $\mathrm{n}$. facialis and $\mathrm{n}$. hypoglossus ${ }^{1,4}$. The results of central reconstruction (dependent much on the persistence, rehabilitation process and patient age) are incomplete. All patients showed a good peripheral innervation, recovered tones of the face and facial movements. Aberrant regeneration excludes differential activity between individual neural rami. Involuntary emotional facial expressions will never recover. Therefore suspenzory facioplastic surgery is indicated in the cases when re-inervation of $\mathrm{n}$. facialis is impossible or other head nerves are also injured.

\section{References}

1. Alexander, E. Jr., Davis, C.H. Jr.: Correction on peripheral paralysis of the facial nerve by hypoglossal-facial anastomosis. South Med J 1954; 47: 299-303.

2. Balance, A.: Surgery of the temporal bone. Vol 2, New York: The Mackmillan Co.;1920. p.578.

3. Balance, C., Duel, A.B.: The operative treatment of facial palsy by introduction of nerve grafts into fallopian canal and by other intra-temporal methods. Arch Otol 1932; 15: 170.

4. Brudny, J., Hammerschlag, P.E., Cohen, N.L., et al.: Electromyographic rehabilitation of facial function and introduction of a facial paralysis grading scale for hypoglossalfacial nerve anastomosis. Laryngoscope 1988; 98: 405-410.

5. Colleman, C.: Results of facial-hypoglossal anastomosis in the treatment of facial paralysis. Ann Surg 1940; 111: 958970.

6. Conley, J.: Hypoglossal-facial anastomosis. In: Brackmann DE, ed. Neurological Surgery of the Ear and Scool Base. New York: Raven;1982. pp.93-98.

7. Evans, D.M.: Hypoglosso-facial anastomosis in the treatment of facial palsy. Br J Plast Surg 1974; 27: 251-257.

8. Faure, J.L. cited by Cushing, H.: The surgical treatment of facial paralysis by nerve anastomosis. Ann Surg 1903; 37: 641-659.

9. Jolesz, F., Sneter, F.: Development, inervation and activity pattern induced changes in skeletal muscle. Ann Res Physiol 1981; 43: 531.

10. Kennedy, R. cited by Cushing, H.: The surgical treatment of facial paralysis by nerve anastomosis. Ann Surg 1903; 37: 641-659.

11. May, M., Sobel, S.M., Mester, S.J.: Hypoglossal-facial nerve interpositional jump graft for facial reanimation without tongue atrophy. Otolaryngol Head Neck Surg 1991; 204: 818826.

12. Schuknecht, H.F.: Pathology of the ear. Cambridge: 
Havard University Press; 1974. p.39.

13. Smith, J. W.: Advances in facial nerve repair. Surg Clin N Amer 1972; 52: 1287-1306.

Matejčík, V.; Pénzesová, G.: Our experience with surgical treatment of lesions of nervus facialis. Neurocirugía 2008; 19: $127-132$.
Correspondence: Department of Neurosurgical Clinic of the Medical Faculty of Comenius University Academician L. Dérer Faculty Hospital. Limbová ul. 5. S33 05 Bratislava. Slovak Republic 